University of Nebraska - Lincoln

DigitalCommons@University of Nebraska - Lincoln

Publications from USDA-ARS / UNL Faculty

U.S. Department of Agriculture: Agricultural

Research Service, Lincoln, Nebraska

2009

Soil Moisture and Metolachlor Volatilization Observations over

Three Years

Timothy J. Gish

USDA-ARS, timothy.gish@ars.usda.gov

John H. Prueger

USDA-ARS

William P. Kustas

USDA-ARS

C. S. T. Daughtry

USDA-ARS

Lynn G. McKee

USDA-ARS

See next page for additional authors

Follow this and additional works at: https://digitalcommons.unl.edu/usdaarsfacpub

Gish, Timothy J.; Prueger, John H.; Kustas, William P.; Daughtry, C. S. T.; McKee, Lynn G.; Russ, Andy; and Hatfield, Jerry L., "Soil Moisture and Metolachlor Volatilization Observations over Three Years" (2009). Publications from USDA-ARS / UNL Faculty. 1366.

https://digitalcommons.unl.edu/usdaarsfacpub/1366

This Article is brought to you for free and open access by the U.S. Department of Agriculture: Agricultural Research Service, Lincoln, Nebraska at DigitalCommons@University of Nebraska - Lincoln. It has been accepted for inclusion in Publications from USDA-ARS / UNL Faculty by an authorized administrator of DigitalCommons@University of Nebraska - Lincoln. 


\section{Authors}

Timothy J. Gish, John H. Prueger, William P. Kustas, C. S. T. Daughtry, Lynn G. McKee, Andy Russ, and Jerry L. Hatfield 


\title{
Soil Moisture and Metolachlor Volatilization Observations over Three Years
}

\author{
Timothy J. Gish, * John H. Prueger, William P. Kustas, C.S.T. Daughtry, Lynn G. McKee, Andy Russ, and Jerry L. Hatfield \\ USDA-ARS
}

A 3-yr study was conducted to focus on the impact of surface soil water content on metolachlor (2-chloro- $N$-(2-ethyl-6methylphenyl)- $N$-(2-methoxy-1-methylethyl) acetamide) volatilization from a field with different surface soil water regimes created by subsurface water flow paths. Metolachlor vapor fluxes were measured at two locations within the field where local meteorological and soil conditions were relatively constant, except for surface soil water content, which differed significantly. Surface soil water content at the two sites differed in response to the presence of subsurface flow pathways. Detailed soil moisture observations over the duration of the study showed that for the first $2 \mathrm{yr}$ (2004 and 2005), surface soil water contents at the dry location (V1) were nearly half those at the wetter location (V2). Cumulative metolachlor vapor fluxes during 2004 and 2005 at V1 were also about half that at V2. In the third year (2006), early-season drought conditions rendered the soil water content at the two locations to be nearly identical, resulting in similar metolachlor volatilization losses. Analysis of infrared soil surface temperatures suggests a correlation between surface soil temperatures and metolachlor volatilization when soils are wet (2004 and 2005) but not when the soils are dry (2006). Field-averaged metolachlor volatilization losses were highly correlated with increasing surface soil water contents $\left(r^{2}=0.995\right)$.
Copyright $\odot 2009$ by the American Society of Agronomy, Crop Science Society of America, and Soil Science Society of America. All rights reserved. No part of this periodical may be reproduced or transmitted in any form or by any means, electronic or mechanical, including photocopying, recording, or any information storage and retrieval system, without permission in writing from the publisher.

Published in J. Environ. Qual. 38:1785-1795 (2009). doi:10.2134/jeq2008.0276

Received 18 June 2008.

*Corresponding author (timothy.gish@ars.usda.gov). (1) ASA, CSSA, SSSA

677 S. Segoe Rd., Madison, WI 53711 USA
$\mathrm{P}$ ESTICIDES are a critical component of modern agriculture and are used worldwide to maintain food and fiber production. Because pesticides appear in the environment where they are not intended and are considered toxic, considerable research has been conducted to quantify the occurrence and impact on the environment. Once applied, pesticides can degrade in situ or move away from the targeted area by leaching into ground water systems, runoff into adjacent streams, and/or volatilize into the atmosphere. Runoff losses of pesticide are typically less than $1 \%$ of that applied, although levels can be exceeded when precipitation occurs immediately after application (Wauchope, 1978; Gaynor et al., 1995). In contrast, volatilization losses can range from 5 to $90 \%$ of the amount applied, depending on the pesticide properties, soil properties, plant residue, management practices, mode of application, and regional and local meteorological conditions (Taylor and Spencer, 1990; Taylor, 1995; Prueger et al., 1999). Once lost to the atmosphere, the range of pesticide transport can result in unintended re-deposition to inhabited (human and animals) areas, streams, rivers, and lakes (McConnell et al., 1998; Alegria and Shaw, 1999; Thurman and Cromwell, 2000; Kuang et al., 2003). A national survey published by the U.S. Environmental Protection Agency (USEPA, 1990) determined that over 10\% of community water system wells contained detectable amounts of at least one pesticide. Although pesticide volatilization has been rigorously studied, current knowledge is lacking for developing a dynamic, physically based model capable of accurately estimating volatilization losses (Van den Berg et al., 1999).

Pesticide transport into the atmosphere involves volatilization of chemical molecules from soil or vegetated surfaces and dispersion into the boundary layer of the atmosphere by diffusion and turbulent mixing (Taylor, 1995). Because pesticides can simultaneously reside in vapor, liquid, and adsorbed phases, factors influencing how the pesticide is partitioned between these phases influence the volatilization process (Jury et al., 1983). The affinity of a specific pesticide for the soil matrix is typically described by an adsorption isotherm (Karickhoff, 1981) that dictates how much of the pesticide may be bound to a surface and as a consequence is not available for leaching or volatilization. For nonionic chemicals, the adsorption process is primarily governed by the soil organic fraction (Rao and Davidson, 1980). Partitioning of a pesticide between liquid and vapor phases is generally a function of a pesticide's affinity for the

T.J. Gish, USDA-ARS Hydrology and Remote Sensing Laboratory, Beltsville, MD; J.H. Prueger, USDA-ARS National Soil Tilth Laboratory, Ames, IA; W.P. Kustas, C.S.T. Daughtry, L.G. Mckee, and A. Russ, USDA-ARS Hydrology and Remote Sensing Laboratory, Beltsville, MD; J. Hatfield, USDA-ARS National Soil Tilth Laboratory, Ames, IA.

Abbreviations: CV, coefficient of variation; GPR, ground-penetrating radar; PUF, polyurethane foam; SFP, subsurface flow pathway. 
soil matrix, saturated vapor density, water solubility, and temperature (Spencer et al., 1969; Spencer and Cliath, 1970). The amount of pesticide distributed among adsorbed, liquid, and vapor phases also depends on the amount of airspace within a soil volume and the thickness of the water molecule layer adsorbed onto the soil particles. As a result, pesticide volatilization is also influenced by soil bulk density, mineralogy, and soil temperature (Rao and Davidson, 1980; Glotfelty et al., 1984).

Most pesticide volatilization studies are of short term, and, although they are useful and informative, they are limited to a single season (Jury et al., 1984; Taylor 1995). The impact of local meteorological conditions on pesticide volatilization is difficult to quantify with single-season studies given the natural year to year meteorological variability. To better evaluate the impact of soil variability and local meteorological influences on volatilization, multi-year investigations using the same pesticide formulations on fields with the same texture, surface residue management, and tillage are needed.

Metolachlor is a broad-spectrum, pre-emergent herbicide used in corn (Zea mays L.), cotton (Gossypium hirsutum L.), soybeans (Glycine max L.), and many other production crops. The National Center for Food and Agricultural Policy estimated that over 26 million kilograms of metolachlor are applied annually (National Center for Food and Agricultural Policy, 2004). As a result, its occurrence in the environment is common. The U.S. Geological Service sponsored a National Water Quality Assessment Program, which reported that $68 \%$ of surface water bodies contained detectable levels of metolachlor (Martin et al., 2003). Surface runoff and leaching were initially thought to be the critical pathways for metolachlor loss (USEPA, 2006) but were later found to be less than $2 \%$ of that applied (Buttle, 1990; Gaynor et al., 2002). Work suggests that, despite a relatively low Henry's Law constant and vapor pressure (Lyman et al., 1990), metolachlor volatilization losses can be significant. Prueger et al. (1999) and Rice et al. (2002) demonstrated that fields under conventional agricultural management practices can have volatilization losses in excess of $12 \%$ of that applied. Furthermore, Prueger et al. (2005) showed that, under certain soil and surface meteorological conditions, metolachlor volatilization can exceed $25 \%$ of that applied.

Soil water content is known to influence pesticide volatilization losses; however, soil water dynamics in a field are rarely monitored continuously. For example, several studies have proposed that soil moisture influences diurnal vapor losses (Glotfelty et al., 1989; Prueger et al., 2005), whereas other studies have shown little night time loss but an increasing vapor loss during the day (Rice et al., 2002). Taylor (1995) proposed that the increases in evening vapor fluxes may be due to a gradual wetting of the soil surface by water vapor condensation that persists through the night until it is evaporated after sunrise. Recently, Prueger et al. (2005) conducted a 5-yr field experiment investigating soil and meteorological factors influencing metolachlor volatilization and showed that volatilization losses at night could be significant, particularly when soil water contents were low. On the other hand, if soil water content was high, the largest volatilization losses occurred during the day. Wolters et al. (2003) recently demonstrated that, although soil moisture was an important factor influencing pesticide volatilization, it was not reflected in present model theory. To better understand the impact of soil moisture on pesticide vapor fluxes, it would be beneficial to quantify volatilization losses where pesticide, soil, and meteorological inputs are identical but where surface soil moisture conditions differ.

Quantifying soil water dynamics in a field is labor intensive, and data interpretation is complex (De Lannoy et al., 2006; Guber et al., 2008). Recent investigations have shown that agricultural fields adjacent to riparian wetlands contain undulating subsurface soil horizons that, due to elevation differences, can funnel water into discrete subsurface pathways (Kung, 1990; Gish et al., 2002). These authors showed that the location of subsurface flow pathways can be estimated using ground-penetrating radar (GPR) and digital elevation maps. Furthermore, Gish et al. (2005) demonstrated that subsurface flow pathways can influence corn yield patterns and soil water content at a depth of $0.1 \mathrm{~m}$. As a result, GPR can be used to identify regions in a field having higher soil water content as a result of subsurface flow pathways that in all other aspects may be similar to neighboring regions within the field.

This paper presents metolachlor volatilization measurements from two sites located in the same field over $3 \mathrm{yr}$ from 2004 to 2006 . The two sites differ with regard to the presence or absence of subsurface flow pathways, which have been shown to influence shallow soil water content that in turn may influence metolachlor volatilization.

\section{Experimental Design Site Description}

The study was conducted at a 21-ha experimental watershed located at the USDA, Henry A. Wallace Beltsville Agricultural Research Center, in Beltsville, Maryland (39 01' 00" N, 76 52' 00" $\mathrm{W})$ and is referred to as the "Optimizing Production inputs for Economic and Environmental Enhancement” (OPE3) site. The soils contain a coarse textured sandy surface and are generally classified as typic hapludults, coarse-loamy, siliceous, mesic. Surface organic matter content in these soils is $<3 \%$. The OPE3 site contains subsurface-restricting layers that have been identified with GPR and reside between 1 and $4 \mathrm{~m}$ below the soil surface (Gish et al., 2002). Although these restricting subsurface soil layers are 1 to $4 \mathrm{~m}$ deep, water flowing above these soil restricting layers can be much shallower. Thus, although the average restricting layer depth at this site is at $1.5 \mathrm{~m}$, the water table may be within $1 \mathrm{~m}$ of the soil surface. Although Gish et al. (2005) demonstrated that averaged corn grain yields decreased with increasing distance from the subsurface flow pathways (during a drought year), they also showed that there were areas where the restricting soil layers (and water above them) were too deep to influence soil water contents and crop yield. Additionally, because the subsurface flow pathways are three dimensional, the depth to the restricting layer varies in depth along the length of the subsurface flow pathways (SFPs). Depressions along the SFPs are common, and these depressions form cascading pools of water when the SFPs are actively flowing. If the SFPs are not flowing (i.e., no lateral water flow), then water that has accumulated previously within these localized "pools" 
behaves as a "local" perched water table. As a result, the GPRidentified SFPs (GPR-SFPs) have a lateral flow and perched water table component. Figure 1 is a color infrared image of fields A and B with their respective SFPs.

Subsurface flow pathways near the two pesticide sampling masts (V1 and V2) have been characterized previously (Gish et al., 2005). Surface soil texture $(0-0.1 \mathrm{~m})$ was determined by collecting eight soil samples from an area within $3 \mathrm{~m}$ of each mast. Composite samples were analyzed in the laboratory. Elevation was determined using a real-time kinematic global positioning system (Table 1). Yield data were used to indicate the approximate size that these two soil moisture regions represent. Yield monitor data near the masts was used to compute an average yield near each mast. Neighboring regions bordering the sam- pling masts with yields within $\pm 0.1 \mathrm{Mg} \mathrm{ha}^{-1}$ were assumed to be similar to the adjacent mast area. These results show that the location that was influenced by a GPR-SFP (V2) represented an area about $400 \mathrm{~m}^{2}$, whereas the area that was not influenced by a GPR-SFP (V1) was larger and represented an area $>600 \mathrm{~m}^{2}$.

Three sets of soil moisture observations were made each year over the duration of the study. This first dataset consisted of gravimetric samples $\left(38.5 \mathrm{~cm}^{2}\right.$ area and $0-5 \mathrm{~cm}$ deep) collected at 0430 (EST) each day from 20 predetermined $1-\mathrm{m}^{2}$ locations within Fields A and B (Fig. 2). These samples were taken within $150 \mathrm{~m}$ of the meteorological station and were used to monitor shallow soil water conditions that were most likely to be in equilibrium with the soil surface. A stratified random design was used each year to select the 20 sampling locations. Fifty percent

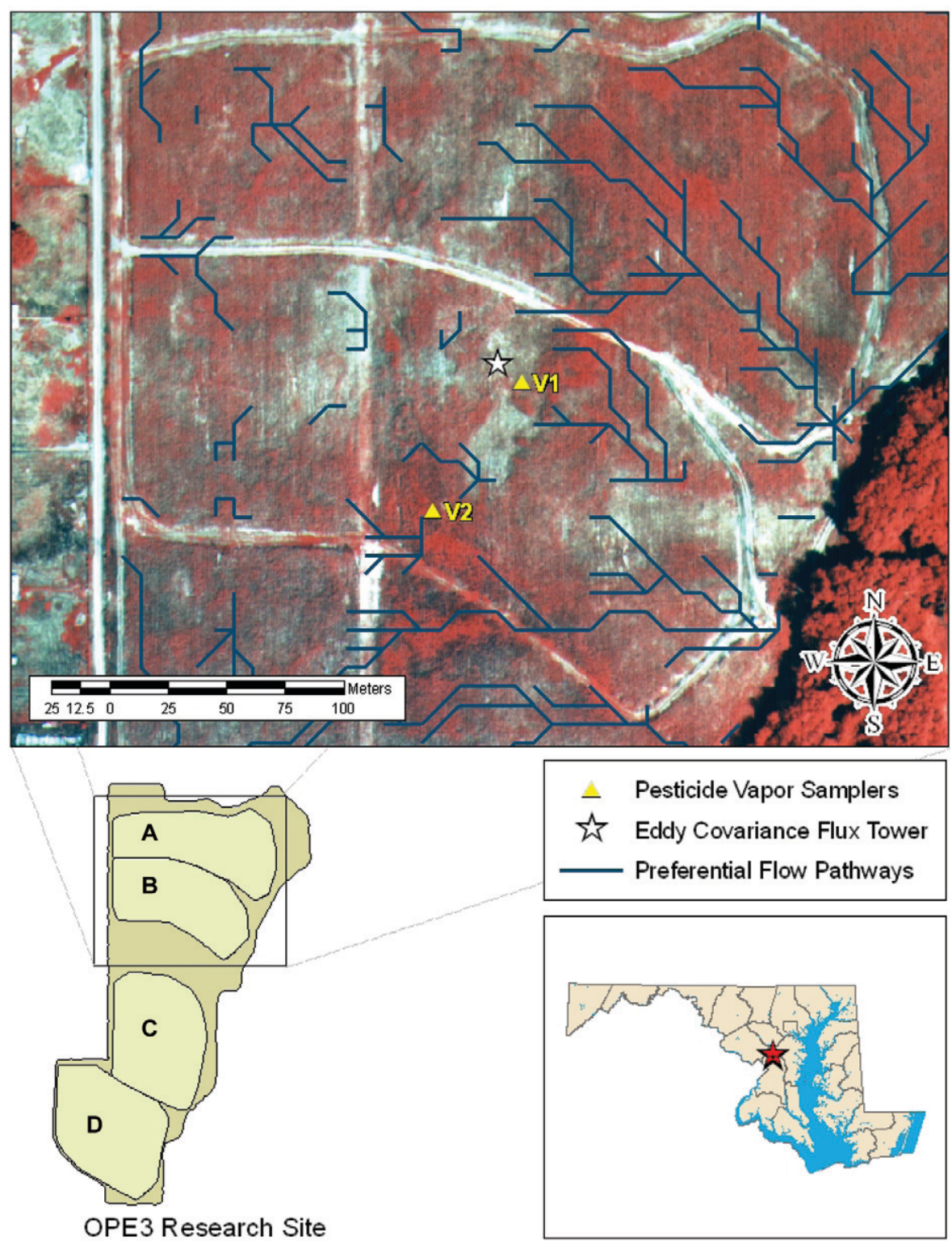

Fig. 1. Color infrared image of Field B at the OPE3 research site. Blue lines denote locations of subsurface flow pathways identified by groundpenetrating radar. This image was taken during a severe drought (1999); as a result, bright red colors indicate high biomass areas where subsurface water favorably influenced plant growth. Bluish gray colors indicate low biomass areas where subsurface water did not affect plant growth (Gish et al., 2005). 
Table 1. Soil and landscape characteristics at the two metolachlor sampling locations.

\begin{tabular}{|c|c|c|c|c|c|}
\hline \multirow[b]{2}{*}{ Locationt } & \multirow{2}{*}{$\begin{array}{c}\text { Organic matter } \\
\text { content }\end{array}$} & \multicolumn{3}{|c|}{ Soil texture‡ } & \multirow[b]{2}{*}{ Elevation§ } \\
\hline & & Sand & Silt & Clay & \\
\hline & & -\% & & - & $\mathrm{m}$ \\
\hline V1: No GPR-SFP & 2.6 & 63 & 22 & 15 & 39.6 \\
\hline V2: GPR-SFP & 3.6 & 65 & 21 & 14 & 39.8 \\
\hline
\end{tabular}

† Mast location relative to the presence or absence of a subsurface flow pathway as identified with ground-penetrating radar.

\# Texture determined using pipette method.

$\S$ Height above mean sea level.

of these soil moisture monitoring sites (10 locations) were randomly selected within $50 \mathrm{~m}$ of the energy balance meteorological station, $40 \%$ of the sites (eight locations) were randomly selected from 50 to $100 \mathrm{~m}$ away, and $10 \%$ (two locations) were located beyond $100 \mathrm{~m}$ of the meteorological station but within the field boundaries (Fig. 2). The other two soil moisture monitoring efforts were collected throughout the day when evaporation could influence surface soil water content and as such might not be in equilibrium with the top few millimeters of soil.

The second soil moisture dataset focused on local measurements made near V1 and V2 in Field B. These measurements were used to evaluate the temporal dynamics of surface soil moisture within a few meters of the pesticide flux mast at V1 and V2 (Fig. 3). For all 3 yr, temporal soil water dynamics at the near-surface location were monitored with dielectric soil moisture probes (Vitel; Stevens Water Monitoring Systems, Inc., Portland, OR), which were installed horizontally at a depth of $5 \mathrm{~cm}$ at two locations $(2 \times 2 \mathrm{~m}$ areas $)$ around V1 and V2. Each dielectric moisture probe used for evaluating temporal soil water dynamics was located about $3.4 \mathrm{~m}$ west of the pesticide flux tower mast because prevailing winds generally were from the west. The probes were connected to a Campbell Scientific 21X data logger (Campbell Scientific, Inc., Logan, UT). All soil moisture readings from dielectric probes were corrected for temperature (Seyfried and Murdock, 2004; Seyfried and

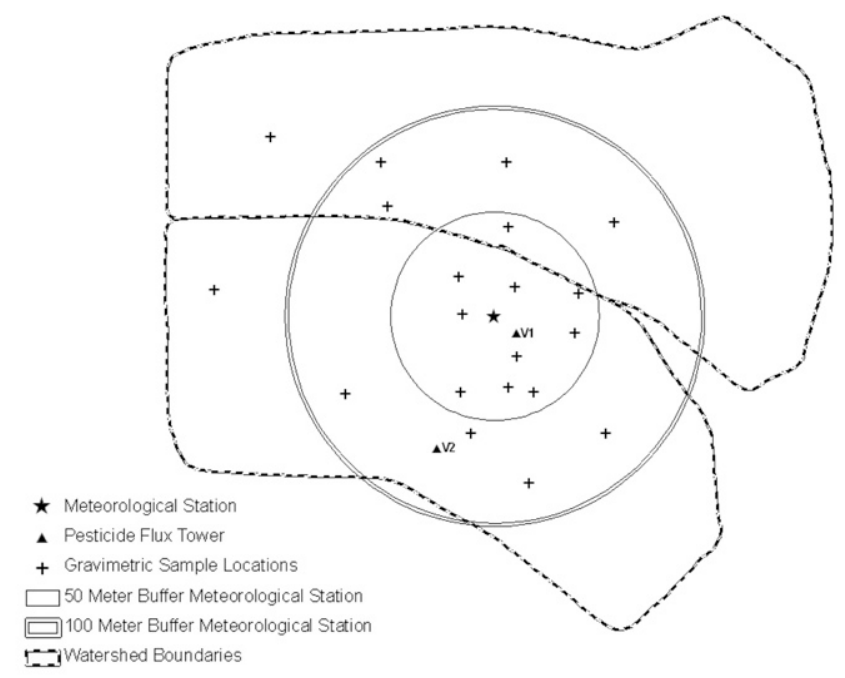

Fig. 2. Schematic showing location of early morning (0430 EST) soil sampling points used to determine surface soil water content that was most likely to be in equilibrium with the shallow soil.
Grant, 2007). Trade names are included for the benefit of the reader and imply no endorsement or preferential treatment of the product listed by the US Department of Agriculture.

The third soil moisture dataset focused on evaluating local spatial variability around each pesticide flux tower near V1 and $\mathrm{V} 2$ in Field B. Three areas $(3 \times 1 \mathrm{~m}$ each $)$ around the pesticide flux mast were monitored using a portable dielectric probe (Theta Probe; Dynamax Inc., Houston, TX) in 2004 or by collecting surface soil samples for gravimetric soil moisture measurements (2005-2006). These measurements were made at random intervals throughout the day and night in 2004, but in 2005 and 2006 measurements were made every $2 \mathrm{~h}$. Regardless of the year, this third dataset generated at least 180 soil moisture observations for each location (V1 and V2) over a 5-d period. The portable dielectric probe measurements generated appreciable variability in soil water content due to location spatial variability (observations taken randomly within the $3 \times 1 \mathrm{~m}$ area (in the row, on top of the row, etc.). As a result, in 2005 and 2006 we changed from portable dielectric probes to gravimetric sampling for monitor the spatial variability of surface soil water content. Bulk density samples were made to augment the gravimetric samples using a soil removal and volume measuring method.

\section{Vapor Flux Gradient Approach}

The vapor flux gradient technique links vertical profile concentrations of metolachlor (2-chloro- $N$-(2-ethyl-6methylphenyl)- $N$-(2-methoxy-1-methylethyl)acetamide) vapor with a pesticide eddy diffusivity term computed from turbulent fluxes of momentum, heat, and water vapor to compute metolachlor fluxes (Baldocchi et al., 1988; Verma, 1990). The flux-gradient theory is based on the assumption that the turbulent transport (surface-atmosphere) of pesticide mass is analogous to molecular diffusion. A pesticide flux is then computed as the product of a mean vertical pesticide concentration gradient and a turbulent-transport coefficient. The flux gradient approach for pesticide flux estimates is based on extending the assumption that transport similarity exists for pesticide vapor as it does for scalar and mass properties of momentum, sensible heat, and water vapor. This is reasonable because only the vapor phase of the pesticide above the soil matrix is of interest here. A more detailed discussion of this approach can be found in Taylor (1995) and Prueger et al. (2005).

Timing of planting and herbicide application varied across years as a function of the local precipitation patterns and techni$\mathrm{cal} /$ logistical problems that are typically encountered with any planting operation. Metolachlor was applied as a surface broadcast spray onto the bare soil surface the day after corn planting. The application rate was $1.51 \mathrm{~kg} \mathrm{ha}^{-1}$ of S-metolachlor.

Metolachlor vapor sampling began approximately $30 \mathrm{~min}$ after applications and continued every $2 \mathrm{~h}$ for the first $120 \mathrm{~h}(5$ d) after application. Each sampling mast had four glass canisters $(0.0254 \mathrm{~m}$ i.d. by $0.15 \mathrm{~m})$ each at a different height $(0.3,0.6,1.2$, and $1.95 \mathrm{~m}$ above the soil surface). The glass canisters were tapered at one end to a $0.0085-\mathrm{m}$ diameter stem and were connected with Tygon tubing to a high-volume air vacuum pump (model TFIA; Staplex, Inc., New York, NY) calibrated to a flow rate of approxi- 
mately $50 \mathrm{~L} \mathrm{~min}^{-1}$ through each sampling canister. The individual canisters were wrapped with aluminum reflective tape to prevent photo degradation of the samples. Each glass canister initially contained two polyurethane foam (PUF) plugs $(0.0254 \mathrm{~m}$ in diameter by $0.075 \mathrm{~m}$ in length) that were pre-cleaned using separate ethyl acetate washes and allowed to air dry. After pre-cleaning, 25 PUF plugs were randomly selected and analyzed as blanks. No interfering peaks were observed above our detection limits. The first PUF plug served as the primary metolachlor vapor trap, and the second in-line PUF plug was analyzed to determine if any pesticide got past the primary PUF. Analysis of the second PUF supports Prueger et al. (2005), who found essentially no metolachlor on the second PUF after the first $24 \mathrm{~h}$ after pesticides had been applied. As a result, after $48 \mathrm{~h}$, each glass canister contained just one PUF pug. Airflow rates through the PUF canisters at each height were measured and recorded at the beginning and end of each sampling interval. After each sampling period, the PUF plugs were placed in glass containers, secured with Teflon-lined lids, and stored in a freezer at $-20^{\circ} \mathrm{C}$.

All PUF plugs were individually extracted with ethyl acetate for $4 \mathrm{~h}$ using a Soxhlet technique. Blank and spike recovery controls were included in sample extraction batches to determine extraction efficiency $(93 \% \pm 11 ; n=23)$ and to detect contamination from laboratory procedures (all blanks were free of interfering peaks). Metolachlor concentrations on the PUF were analyzed using a Hewlett-Packard 5890 Series II GC equipped with a nitrogen phosphorous detector. Method quantification limits for metolachlor were $10 \mathrm{ng}$, well above the baseline noise level, corresponding to ambient air concentrations of $2 \mathrm{ng} \mathrm{m}^{-3}$.

\section{Surface and Energy Balance/Meteorological Instrumentation}

Surface energy balance and eddy covariance instrumentation to measure net radiation, soil heat flux, and sensible and latent heat flux densities were mounted on a 10-m tower near the V1 sampling site. Net radiation and soil heat flux were measured with a CNR-1 net radiometer (Kipp \& Zonen, Bohemia, NY) and three HFT1 soil heat flux plates (Radiation Energy Balance Systems, Seattle, WA), respectively. The CNR-1 was positioned $4 \mathrm{~m}$ above the surface, and the soil heat flux plates were buried $0.08 \mathrm{~m}$ below the soil surface. Above each soil heat flux plate at 0.02 and $0.06 \mathrm{~m}$ depth were two Type-T (copper-constantan) soil thermocouples. Soil temperature data were used to compute the storage component of the above-the-soil heat flux plates. A 3-D sonic anemometer (Campbell Scientific, Logan, UT) and an infrared hygrometer (LI7500; LICOR, Lincoln, NE) measured sensible and latent heat fluxes as the covariance of the vertical wind velocity with air temperature and water vapor density. Soil surface temperatures were monitored using Precision Infrared Thermocouple Sensors (Model IRTS-P; Apogee Instruments, Logan, UT) that were monitoring an area of about $0.5 \mathrm{~m}^{2}$. Standard local surface meteorological instrumentation was also mounted on the tower to measure mean wind speed and direction, relative humidity, and precipitation. A second 3-m tower was erected at the site to monitor air temperature, humidity, and wind

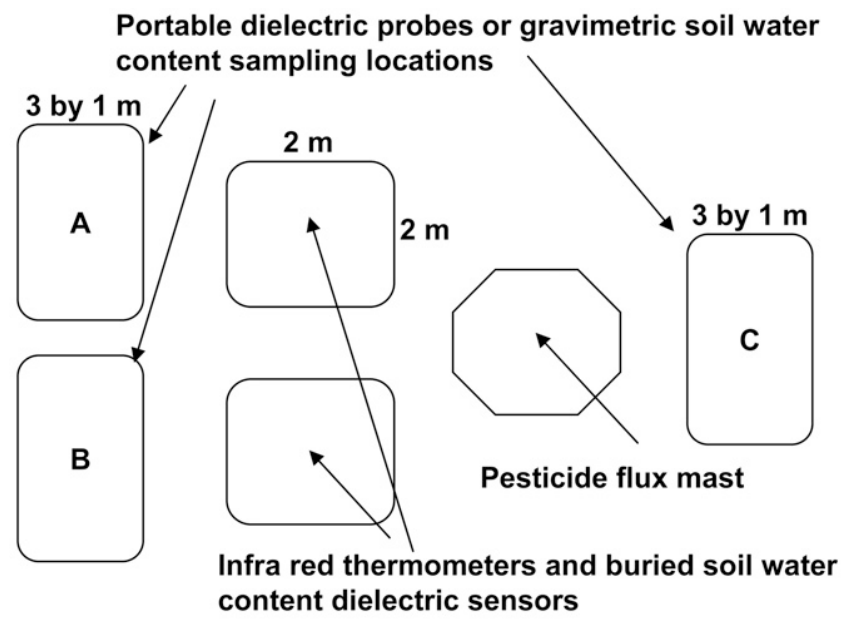

Fig. 3. Schematic of the instrumentation and sampling locations near V1 and V2. Buried dielectric sensors $(5-\mathrm{cm})$ and infrared thermometers ( $1 \mathrm{~m}$ above the soil surface) were placed at the center of the $2 \times 2 \mathrm{~m}$ areas. Portable dielectric probes or gravimetric sampling took place within the $3 \times 1 \mathrm{~m}$ regions.

speed at heights above the soil surface. This information was used to characterize near-surface stability conditions. Sampling frequency was $20 \mathrm{~Hz}$ for the eddy covariance and $10 \mathrm{~s}$ for the energy balance and all meteorological instrumentation. All data were stored as 30min averages on Campbell 5000, 23x and 21x data loggers.

\section{Results and Discussion}

\section{Soil Comparison at Two Mast Locations}

The entire OPE3 site received the same tillage practice and metolachlor formulations during the 3-yr study. Soil characteristics at the locations have nearly identical elevations in addition to sand, silt, and clay percentages (Table 1). However, the field location with a GPR subsurface flow pathways (GPRSFP) (V2) had an organic matter content of 3.6\% that was slightly higher than the location without a nearby GPR-SFP (V1), where the organic matter content was 2.6\%. Although the two locations have similar soil characteristics, the two sites differed with respect to corn grain production during a drought year (1999). During a drought, the location without a nearby GPR-SFP (V1) had a grain yield of only $0.1 \mathrm{Mg} \mathrm{ha}^{-1}$, whereas $66 \mathrm{~m}$ away, the location with a nearby GPR-SFP (V2) had a yield of $1.3 \mathrm{Mg} \mathrm{ha}^{-1}$, which is nearly an order of magnitude greater. The significant increase in yield, and perhaps the higher organic matter content, is likely due to the presence of a nearby GPR-SFP that came within $1.5 \mathrm{~m}$ of the soil surface. Although research on subsurface flow pathways is in its infancy, Gish et al. (2005) demonstrated that on average, corn grain yields increased near subsurface flow pathways during water-limiting years. They also noted increases in yield and biomass during a drought as well as during years with average precipitation that may, in part, account for the slightly higher organic matter content near V2. In short, both field locations have similar soil characteristics but differ primarily with regard to the presence or absence of a GPR-SFP. 


\section{Soil Moisture Observations}

Because subsurface flow pathways can influence shallow soil water content, precipitation history is important in determining how active the subsurface flow pathways were during the volatilization experiments as well as the general soil moisture status of the OPE3 site before application. Precipitation totals at the OPE3 site 3 mo before application for 2004, 2005, and 2006 were 221, 190, and $92 \mathrm{~mm}$, respectively. Because evapotranspiration is minimal during the winter and early spring, much of this water should be available for subsurface transport. As a result, the impact of the GPR subsurface flow pathways may be more easily observed in 2004 and 2005 than in 2006. In addition, the first of three soil moisture monitoring effort reflects these yearly differences in precipitation. This first soil moisture dataset consisted of gravimetric soil water content sampled just before sunrise each day. Because the locations for this 0430 surface moisture observation were randomly selected with Fields A and B, it is not possible to use this dataset to distinguish differences between the V1 and V2 locations (which were both located in Field B). However, this 0430 surface moisture dataset should be in equilibrium with the surface few millimeters of soil (Table 2). For example, during the first 48 $\mathrm{h}$ after application, a period when metolachlor volatilization is highest, 2004 was the wettest, with an average gravimetric water content (on this sandy soil) of $18 \%$. In comparison, for the first $48 \mathrm{~h}$ after application during 2006, the average gravimetric water content was $10 \%$, with 2005 being in between these 2 yr with a $48 \mathrm{~h}$ average of $13 \%$ soil moisture. In summary, precipitation and field-averaged soil moisture observations taken at 0430 indicate that 2004 was the wettest and 2006 the driest. Because $90 \%$ of the 0430 moisture readings are within $100 \mathrm{~m}$ of the pesticide flux towers (Fig. 2), these observations may be useful in approximating possible soil water effects for the averaged metolachlor volatilization losses (averaging V1 and V2 metolachlor volatilization). Furthermore, if the GPR subsurface flow pathways are to affect metolachlor volatilization, the precipitation data indicate that any impact should be more readily observed in 2004 and 2005 than 2006 in the comparison between the two sampling locations.

The second soil moisture dataset was collected throughout the day near the sampling masts (Fig. 3) and reflects localized variability in soil water content between the two mast locations. Even at this small scale, spatial variability in shallow soil water content was considerable at both locations, with CVs ranging from 15 to $37 \%$ (Fig. 4). During 2004, 966 measurements with dielectric probes

Table 2. Averaged early morning gravimetric surface soil water content (\%) as a function of time after application. $\downarrow \S$

\begin{tabular}{lcrrrrr}
\hline & Day of & \multicolumn{4}{c}{ Days after application } \\
\cline { 3 - 7 } Year & application & $\mathbf{1}$ & $\mathbf{2}$ & $\mathbf{3}$ & \multicolumn{4}{c}{} & \multicolumn{5}{c}{$\mathbf{5}$} \\
\hline 2004 & 18.1 & 18.5 & 15.1 & 14.2 & 13.4 & 16.5 \\
2005 & 13.0 & 13.1 & 12.7 & 12.3 & 14.2 & 18.8 \\
2006 & 10.6 & 10.3 & 9.6 & 10.0 & 9.2 & 13.7 \\
\hline
\end{tabular}

† Average of 20 samples taken from $201-\mathrm{m}^{2}$ locations, randomly selected each year.

₹ Represents the average soil water content at the time of pesticide application, samples collected from 1 to $30 \mathrm{~min}$ after pesticide application.

$\S$ Soil moisture samples were collected at 0430 (EST) each day for the first $5 \mathrm{~d}$ after pesticide application. revealed averaged CVs of 37\% for V1 and V2. In 2006, 474 gravimetric soil water content observations generated an averaged CV of $18 \%$ for V1 and 19\% for V2. However, during 2005, only 258 gravimetric soil measurements were made, and these showed more spatial variability at V1 than V2, with CVs of 25 and $15 \%$, respectively. Variation in surface soil water contents of this magnitude is common. In a recent watershed experiment, soil water content at the surface as well as those measured at $5-\mathrm{cm}$ depth frequently exhibited CVs between 15 and 40\% (Choi and Jacobs, 2007).

The third soil moisture dataset focused on evaluating the temporal dynamics of shallow soil moisture (Fig. 4). With spatial variability in soil water content known, the relative uncertainty around the temporal moisture observations can be estimated. In 2004, dielectric probes were used to measure volumetric water content, but in 2005 and 2006 the gravimetric approach was used. Variability in soil bulk density measurements was minimal; observations ranged from 1.1 to $1.3 \mathrm{~g} \mathrm{~cm}^{-3}$. Additionally, the soil bulk densities exhibited a mean of $1.27 \mathrm{~g} \mathrm{~cm}^{-3}$ and a CV of $4.7 \%$. With variability in measured soil bulk densities $<5 \%$, volumetric water content can be calculated for 2005 and 2006 with reasonable confidence. The results show that although the CVs between the two locations were often similar during a given year, the magnitude of local soil water content variation was different because V2 tended to be wetter than V1. As a result, during 2004, the SD in surface soil water content was calculated as $0.038 \mathrm{~cm}^{3}$ water $\mathrm{cm}^{-3}$ soil for location $\mathrm{V} 1$, whereas it was $0.065 \mathrm{~cm}^{3}$ water $\mathrm{cm}^{-3}$ soil for V2. In 2005, the average SDs of the soil water content at $\mathrm{V} 1$ and $\mathrm{V} 2$ were 0.028 and $0.039 \mathrm{~cm}^{3}$ water $\mathrm{cm}^{-3}$, respectively. In 2006, the average SDs of the soil water content at V1 and V2 were 0.018 and $0.042 \mathrm{~cm}^{3}$ water $\mathrm{cm}^{-3}$, respectively. The large spatial uncertainty in soil water content coupled with similar temporal soil water content observations at V1 and V2 (Fig. 4) indicate that in 2006 these two locations were not significantly different. In summary, although the site characterization indicates that V1 and $\mathrm{V} 2$ are nearly identical, local shallow soil water content measurements made throughout the day indicate that the location nearby a GPR identified subsurface flow pathway, V2, was wetter than V1 in 2004 and 2005 but not in 2006.

\section{Metolachlor Volatilization}

Cumulative metolachlor vapor losses as a function of time after application are significantly different for the two within-field locations (Fig. 5). Metolachlor volatilization losses were greatest in 2004 when field scale soil water content was greatest; conversely, when soil water content was lowest (in 2006), metolachlor volatilization was the least. Metolachlor volatilization between locations V1 and V2 are also supported by differences in soil water content. During 2004, cumulative metolachlor vapor losses at V2 were 29,145 $\mathrm{ng} \mathrm{m}^{-2}$, compared with $17,261 \mathrm{ng} \mathrm{m}^{-2}$ at V1. During 2005, V2 cumulative vapor losses were $15,193 \mathrm{ng} \mathrm{m}^{-2}$, compared with $7246 \mathrm{ng}$ metolachlor $\mathrm{m}^{-2}$ at V1. Consequently, during 2004 and 2005, when the subsurface flow pathways are most likely to be active, metolachlor loss vapor losses were almost twice as large at V2 as those observed at V1. The primary difference between these locations was that shallow soil water content at V2 was nearly double that of V1. During 2006, when soil 
water content levels between the two metolachlor sampling sites were similar, cumulative metolachlor loss at V2 was $5405 \mathrm{ng} \mathrm{m}^{-2}$ compared with $5317 \mathrm{ng} \mathrm{m}^{-2}$ soil at V1. Similar volatilization losses between V1 and V2 in 2006 support the perspective that these two locations are indeed similar, with the exception of soil moisture, which is likely in response to meteorological conditions and the existence of SFP. Additionally, because soil organic matter is the principle adsorption site for metolachlor (Rao and Davidson, 1980), locations with higher soil organic matter content should have corresponding lower volatilization losses if all other factors are constant (Jury et al., 1983). However, because metolachlor volatilization fluxes were higher at $\mathrm{V} 2$ relative to $\mathrm{V} 1$ and because soil texture, plant residue management, and climatic inputs are identical, soil moisture is likely the primary factor contributing to differences in metolachlor volatilization losses between these sites.

Although soil water content clearly has an impact on metolachlor volatilization, the role and interaction with meteorological variables has not been clearly identified (Prueger et al., 2005). However, because metolachlor volatilization was monitored continuously, the impact of daytime and night-time pesticide losses can be more clearly investigated. During the first $120 \mathrm{~h}$ after application, night-time (2000-0600 h) cumulative metolachlor vapor losses ranged from $2385 \mathrm{ng} \mathrm{m}^{-2}$ to $4644 \mathrm{ng} \mathrm{m}^{-2}$. For two of the three years (2005 and 2006), night-time vapor losses of metolachlor were nearly identical (Fig. 6), with 2004 being slightly higher. Thus, significant, night-time metolachlor volatilization loss is relatively constant when compared with cumulative metolachlor losses (Fig. 5). In addition, differences in night-time metolachlor volatilization between V1 and V2 were minor, ranging from $518 \mathrm{ng} \mathrm{m}^{-2}$ in 2004 to $723 \mathrm{ng} \mathrm{m}^{-2}$ in 2006. These results support the conclusion that daytime pesticide volatilization can be considered as an energy-driven process. Daytime conditions are characterized by strong solar radiation, surface heating (increased surface layer instability), and increased water vapor gradients, all of which drive maximum evapotranspiration processes that are coupled with upward movement of soil water in response to increased evapotranspiration. In contrast, nighttime conditions represent periods of low available energy, stable surface conditions, and low water vapor gradients, which result in low to zero evapotranspiration. These general diurnal trends affect the metolachlor volatilization at the surface. As a result, it does not appear that differences in surface soil water content had an impact on night-time metolachlor volatilization.

Cumulative metolachlor volatilization at V1 and V2 occurred predominantly during daylight hours (0600-2000) and especially when the soil surface was wet (Fig. 7). In 2004, 84\% of the metolachlor volatilization occurred during daylight hours when field scale early morning soil water contents were the highest (Table 2). Differences in daytime volatilization losses (V1 and V2) were also significant in 2004 , with $13,134 \mathrm{ng} \mathrm{m}^{-2}$ of metolachlor volatilization at V1, compared with 24,500 $\mathrm{ng} \mathrm{m}^{-2}$ at the wetter location, V2. Likewise, during 2005, about $80 \%$ of the metolachlor volatilization occurred during daytime hours. Only $4893 \mathrm{ng} \mathrm{m}^{-2}$ metolachlor volatilized at V1 during the day, compared with $12,132 \mathrm{ng} \mathrm{m}^{-2}$ at V2 in 2005. However, in 2006, when soil mois-
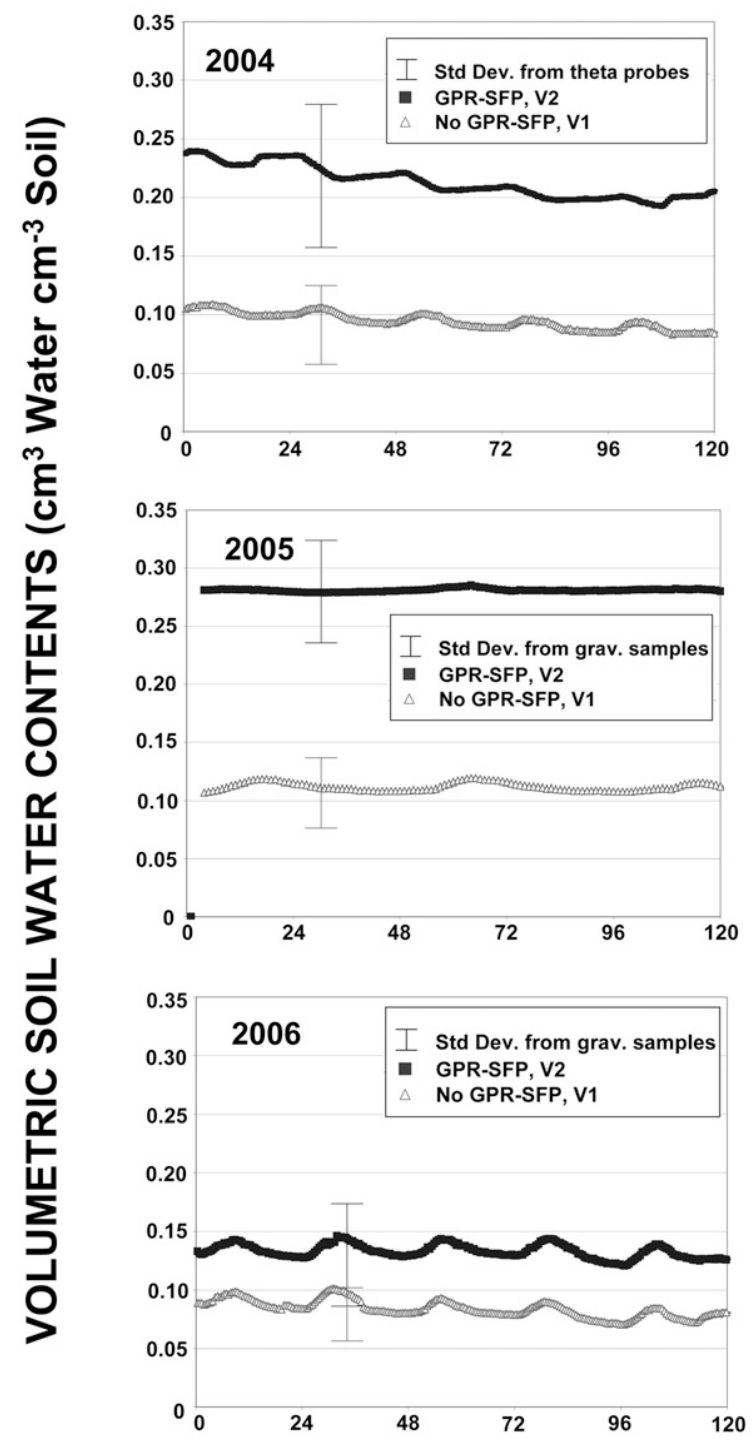

TIME (hours after pesticides applied)

Fig. 4. Temporal dynamics of shallow soil water content measured with dielectric probes (centered at $5 \mathrm{~cm}$ ) for two locations. Error bars represent 1 SD. Standard deviations were estimated with dielectric probes (2004) or gravimetric sampling and soil bulk density measurements. V1 is located in an area without groundpenetrating radar (GPR) identified subsurface flow pathways (No GPR-SFP), and V2 is located in an area $66 \mathrm{~m}$ away that has nearby GPR-identified subsurface flow pathways (GPR-SFP).

ture observations were low (Table 2) and exhibited similar contents between V1 and V2 (Fig. 4), almost no difference in cumulative metolachlor vapor losses was observed, with $3108 \mathrm{ng} \mathrm{m}^{-2}$ at V2 and $2385 \mathrm{ng} \mathrm{m}^{-2}$ at V1. In 2006, V1 and V2 had low soil water content, but dry soil conditions favor pesticide adsorption (Taylor and Spencer, 1990). Because dry soils favored adsorption in 2006, the reduction in metolachlor vapor losses at V2 relative to V1 may be due to the larger organic matter content (and higher surface areas) at V2 (Table 1). In general, the enhanced daylight loss of metolachlor is supported by earlier findings by Glotfelty et al. (1989), Rice et al. (2002), and Prueger et al. (2005), who observed the largest volatilization loss to occur during daylight 

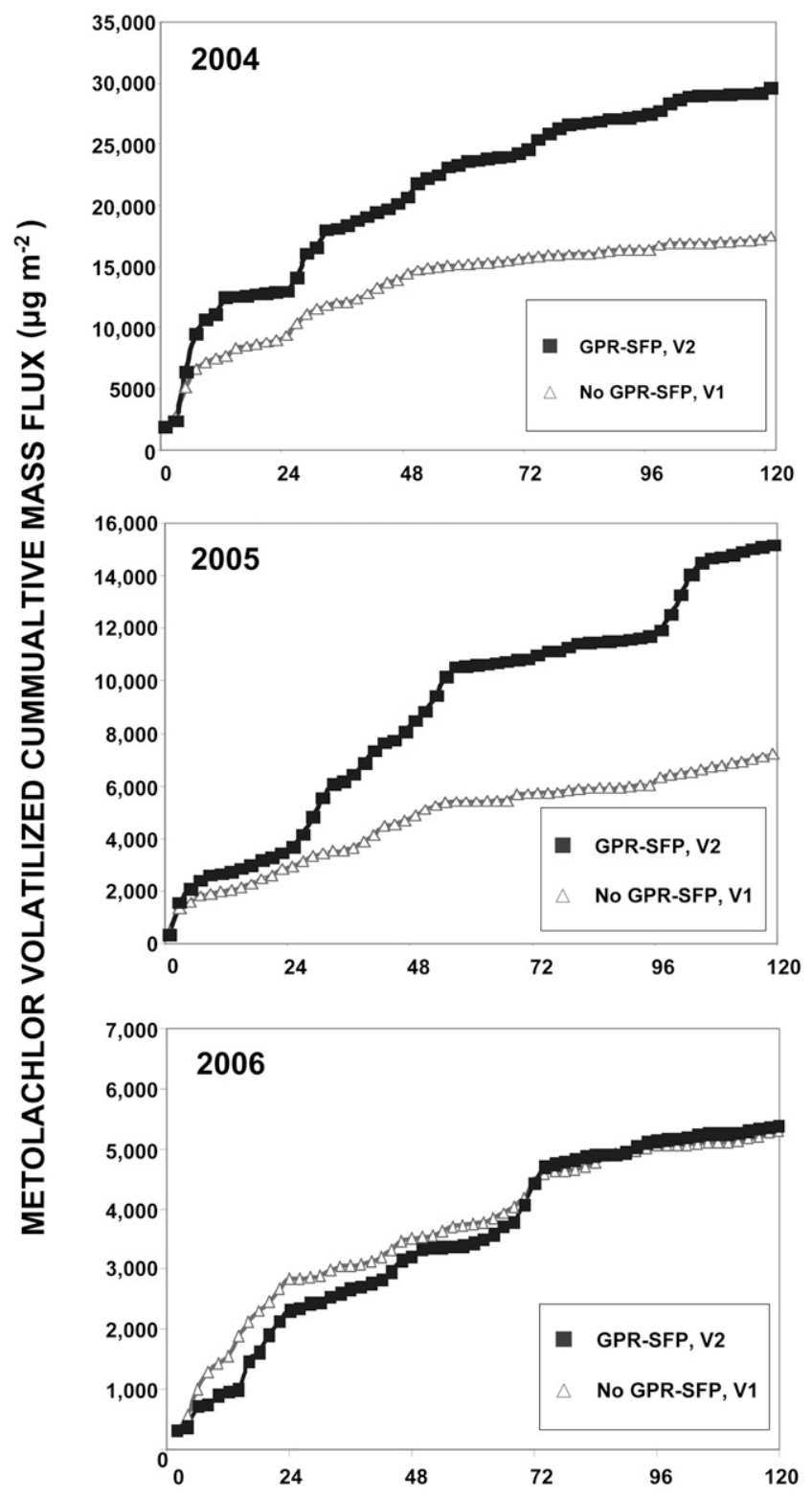

TIME (hours after pesticide application)

Fig. 5. Cumulative metolachlor vapor fluxes after $120 \mathrm{~h}$ from application for both field locations for 2004, 2005, and 2006. The $y$ axis has different scales.

hours. On any given year, with soil properties similar and climatic inputs the same, the enhanced volatilization during the day at V2 relative to V1 in 2004 and 2005 appears related to differences in soil water content and/or meteorological conditions. As a result, daytime metolachlor losses are critical to total metolachlor volatilization losses, and it appears that as the shallow soil water content increases, so does metolachlor volatilization.

Temporal dynamics and diurnal vapor fluxes of metolachlor are shown in Fig. 8 (open squares). Regardless of year, metolachlor volatilization decreases with time. When soils were wettest (in 2004), metolachlor volatilization rates were greatest, with over $4000 \mathrm{ng} \mathrm{m}^{-2}$ lost during a 2-h period. When soils were the driest (in 2006), the lowest volatilization rates $\left(<500 \mathrm{ng} \mathrm{m}^{-2}\right)$ during the first $48 \mathrm{~h}$ af-
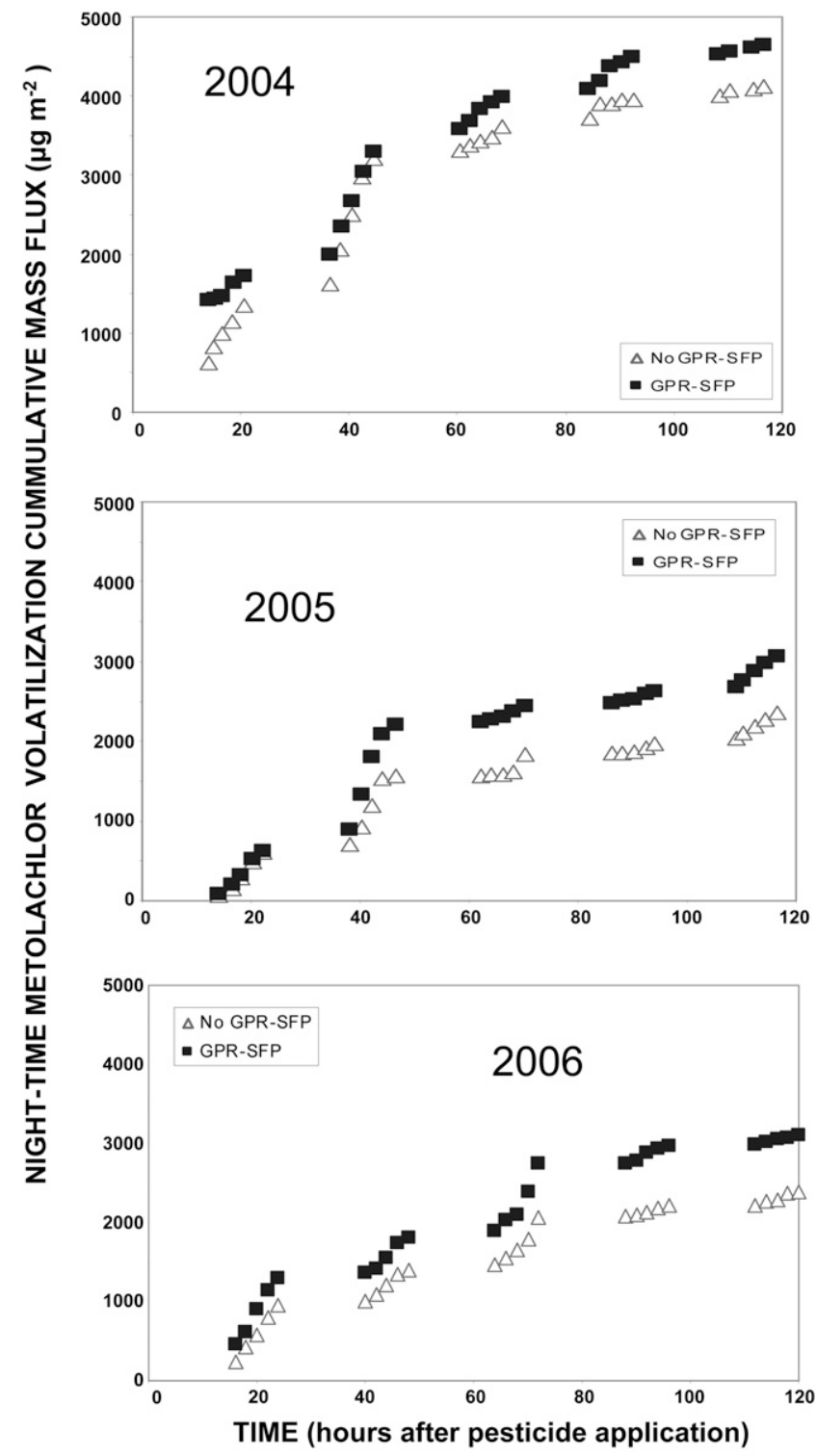

Fig. 6. Night-time cumulative metolachlor vapor fluxes after $120 \mathrm{~h}$ from application for both field locations for 2004, 2005, and 2006. The $y$ axis has same scale.

ter application were observed. The phenomena reported by Taylor (1995) and Prueger et al. (2005) of increased volatilization occurring in the early evening and morning was also observed in this study, especially when soil was the driest. In addition, if precipitation occurred after the first $48 \mathrm{~h}$, metolachlor volatilization peaks were subsequently observed (see hour 96 in 2005 and hour 72 in 2006). As a result, soil water content strongly affects metolachlor volatilization rates. In addition, the temporal dynamics of metolachlor volatilization appear to be related to surface soil temperature and surface soil water content. For example, Fig. 8 shows the relationship between observed surface soil temperatures (solid squares) as quantified with remotely sensed infrared sensors and metolachlor vapor flux loss rates at $\mathrm{V} 2$. When soils were wet, metolachlor vapor flux rates and surface soil temperatures peaked together (in phase). As a result, when soils are wet and energy is available, metolachlor volatilization is enhanced. However, when soil water content is low 

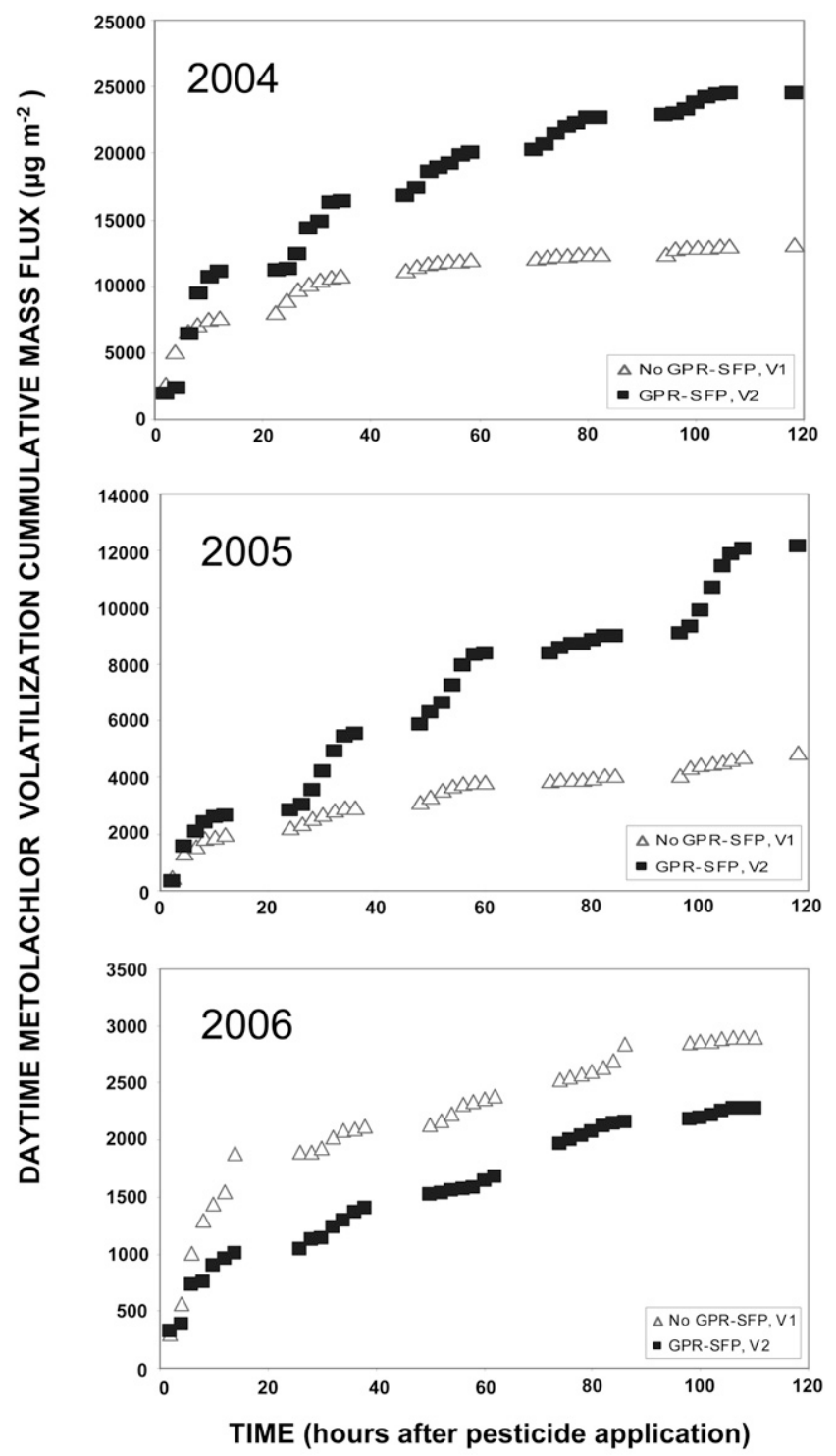

Fig. 7. Day-time cumulative metolachlor vapor fluxes after $120 \mathrm{~h}$ from application for both field locations for 220, 2005, and 2006. The $y$ axis has different scales.

(as in 2006), peak volatilization rates no longer coincide with surface soil temperatures. This latter trend was also observed at the drier location (V1), where metolachlor vapor flux rates failed to correlate with surface soil temperatures (Fig. 9). In short, when soils are wet, there is a link with surface temperatures that results in increased metolachlor vapor losses, but as soils dry out, no relationship with surface soil temperature is evident.

Although the data support the hypothesis that as surface soil water content increases so does metolachlor volatilization, it is difficult to quantify an exact relationship due to differences in scale. For example, soil moisture observations are on the scale of a few $\mathrm{cm}^{2}$, whereas meteorological variables correspond to tens to hundreds of $\mathrm{m}^{2}$. This limitation also restricts our ability to better quantify meteorological and soil water content relationships with metolachlor volatilization. However, a first approximation of the impact of soil water on metolachlor volatilization can be determined by averaging metolachlor vapor losses from V1 and
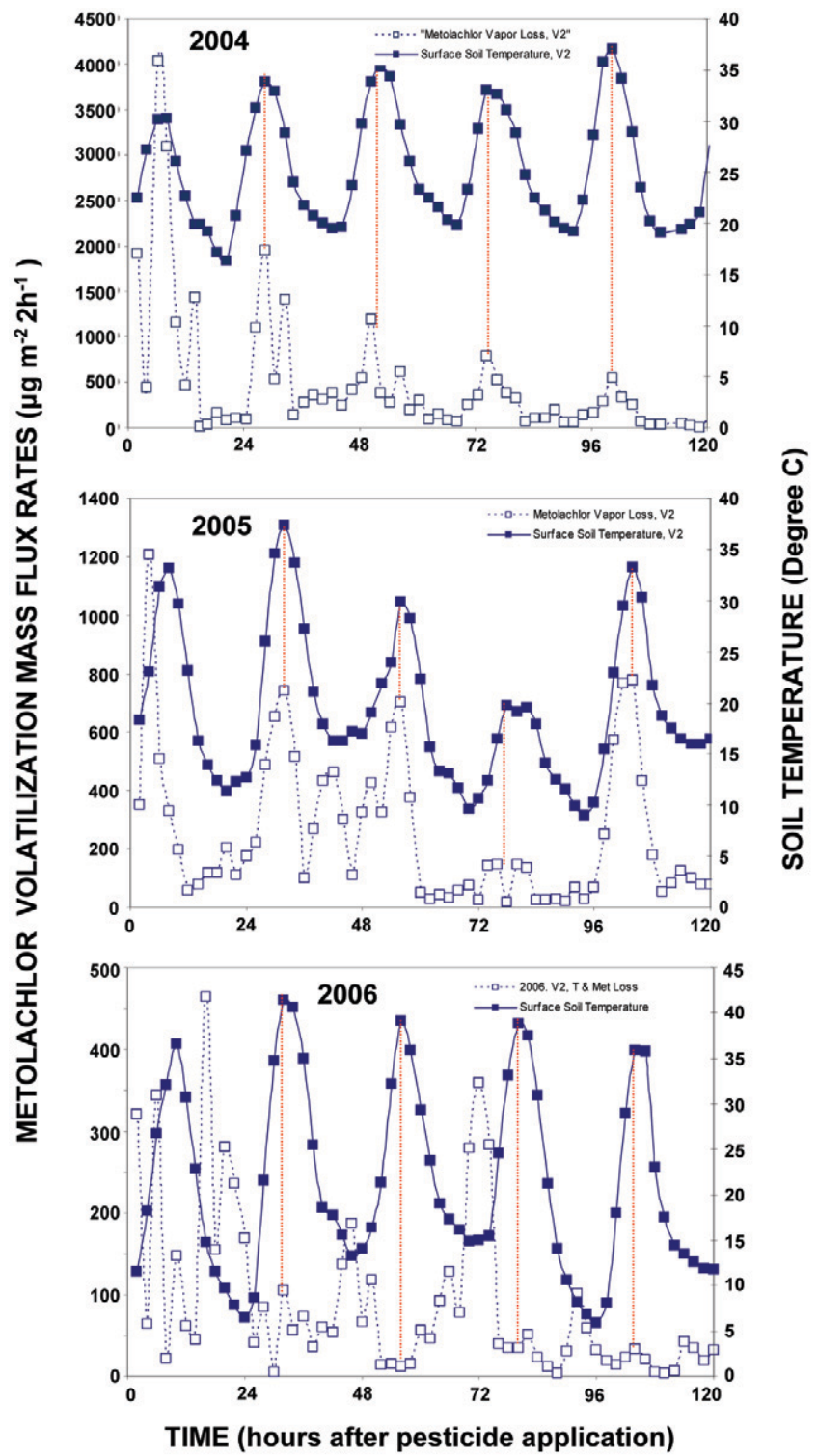

Fig. 8. Relationship between metolachlor vapor flux rates at V2 (ground-penetrating radar-identified subsurface flow pathways) with surface soil temperatures as determined with infrared thermocouple, for 2004, 2005, and 2006. Note the different scales for metolachlor $y$ axis. Vertical dotted red lines visually link times when peak metolachlor volatilization flux rates occurred relative to corresponding soil surface temperatures.

V2 relative to averaged surface soil water contents determined before sunrise (Fig. 10). For Figure 10, soil water contents taken at the time of application and the next two 0430 measurements in Field A and B (Fig. 2) were averaged and compared with average metolachlor volatilization losses from V1 and V2 during the same time interval. Prueger et al. (2005) demonstrated that the vast majority of the metolachlor volatilizes within the first 48 to $72 \mathrm{~h}$ after application. Agreement is excellent, with field-averaged metolachlor volatilization losses increasing exponentially with increasing field-averaged surface soil water content $\left(r^{2}=0.995\right)$. Although preliminary, these results are qualitatively supported by the work of Prueger et al. (2005), who also postulated increasing metolachlor losses with increasing water contents. 

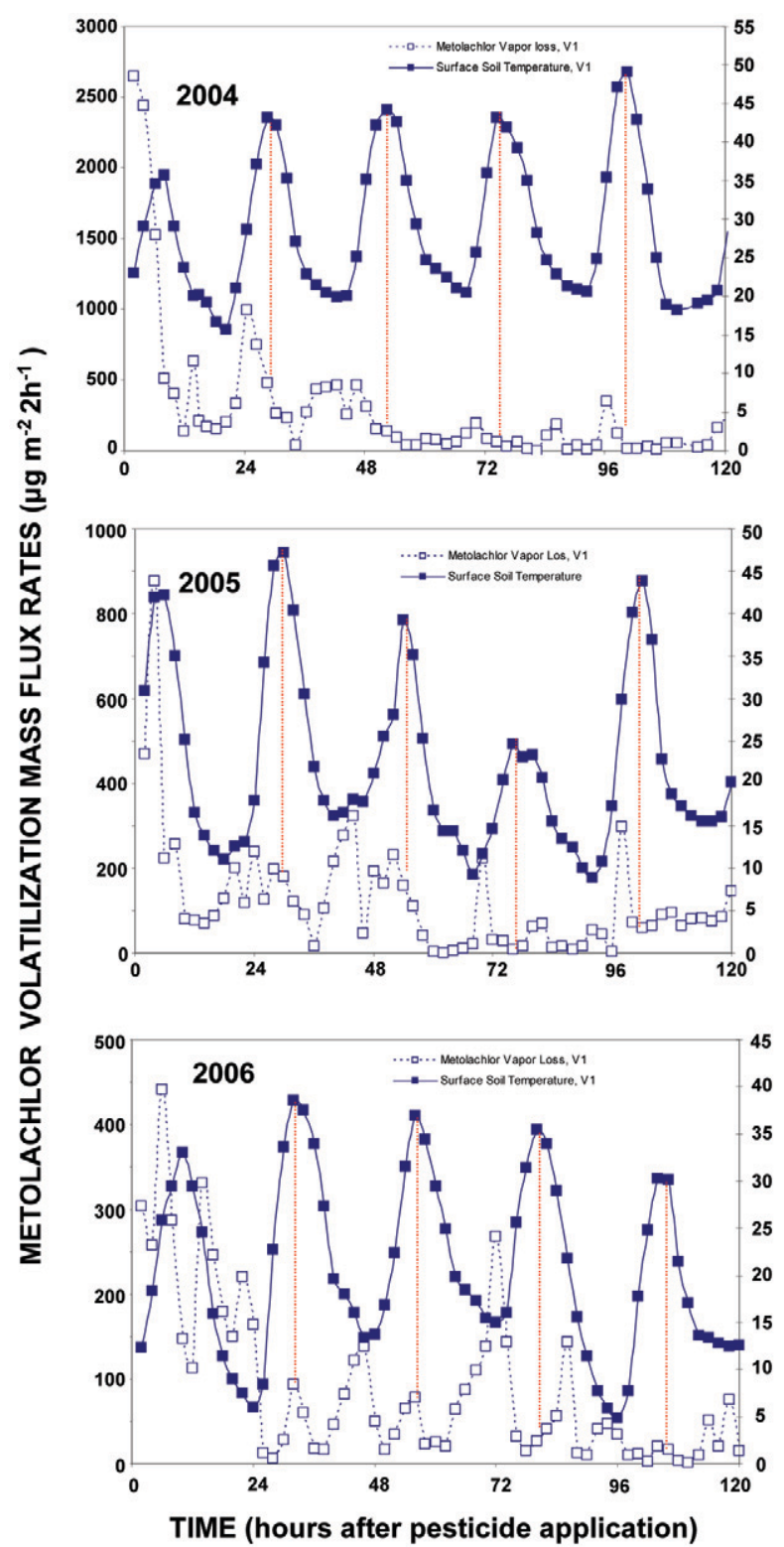

Fig. 9. Relationship between metolachlor vapor flux rates at V1 (ground-penetrating radar-identified subsurface flow pathways) with surface soil temperatures as determined with infrared thermocouple for 2004, 2005, and 2006. Note the different scales for metolachlor $y$ axis. Vertical dotted red lines visually link times when peak metolachlor volatilization flux rates occurred relative to corresponding soil surface temperatures.

Future work is needed to determine how to quantify largescale surface soil moisture contents (within the upper few millimeters of soil) with present point measurement technologies. Determining representative surface soil water content in the top few millimeters is not feasible with the present monitoring approaches because spatial variability in point measurements is considerable. Until a representative surface soil moisture measurement technique is developed, it will be difficult to quantify direct relationships between meteorological factors, pesticide chemistry, and soil properties. It may be necessary to develop methods like remote sensing to better quantify area soil water content so that soil moisture, temperature, and pesticide vapor

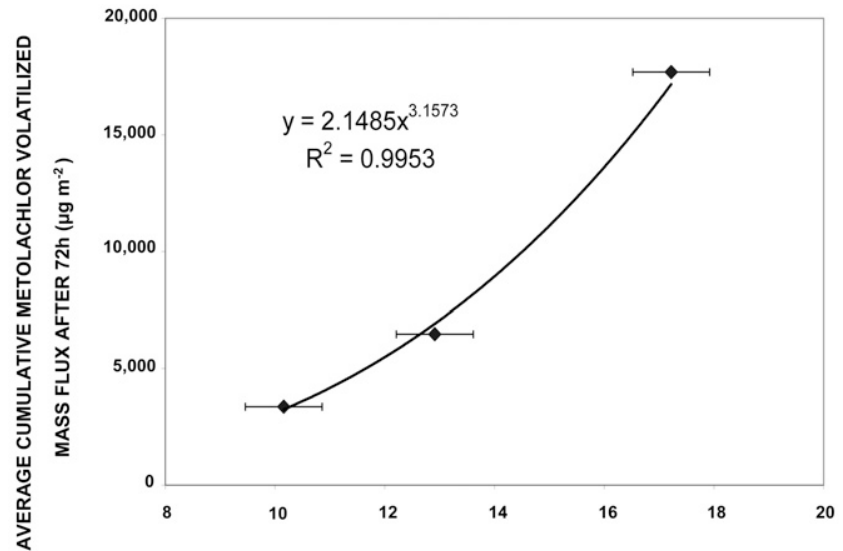

AVERAGED FIELD GRAVIMETRIC WATER CONTENTS ( $\mathrm{g}$ water $\mathrm{g}$ soil $^{-1}$ )

Fig. 10. Relationship between field-averaged metolachlor vapor fluxes (V1 and V2) with averaged gravimetric surface soil water contents (20 samples collected at 0430 each day).

flux footprints may be of similar scale. However, it does appear that, with respect to soil particles, there may be preferential adsorption for the water molecules over that of the metolachlor molecules. Increased soil water content would lead to the dissociation or displacement of the metolachlor molecules from the surface of the soil particles. With respect to temperature (radiometric or surface temperature), increases in temperature are correlated with increases in metolachlor vapor pressure, which may result in greater volatilization losses. This depends on such things as surface soil water content, organic matter, wind speed, and stability conditions (i.e., day vs. night local surface meteorological conditions).

\section{Conclusion}

Pesticide volatilization has been identified as a critical loss pathway whereby agricultural pesticides can enter the boundary layer of the atmosphere and be redeposited in unintended areas of the environment. In this 3-yr study, we focused on evaluating the impact of surface soil moisture on metolachlor volatilization. Metolachlor vapor fluxes were measured at two locations where surface soil water content was significantly different but where local meteorological inputs, soil properties (except for minor differences in the organic matter content), pesticide formulation, plant residue management, and elevation were identical. Results demonstrate that:

- Metolachlor volatilization increased significantly with increasing surface soil water content.

- Metolachlor volatilization rates and cumulative losses can be significantly different over a spatial distance of $66 \mathrm{~m}$, particularly if subsurface flow pathways are prevalent.

- Surface soil water content is a critical factor influencing metolachlor volatilization during daylight hours. For a given year, a doubling of the surface soil water content (5-cm depth) generally resulted in more than a doubling of the cumulative daytime metolachlor volatilization losses. For pesticide volatilization to be effectively modeled, surface soil moisture must be understood and coupled with meteorological conditions. 
- Surface soil temperature and metolachlor vapor fluxes rates were coupled when surface soil water content was high, but as soils dried this trend became decoupled.

- Metolachlor flux rates at night are significant but are not heavily influenced by soil moisture. Because night-time metolachlor vapor losses were fairly constant regardless of soil conditions, it can account for as much as $50 \%$ of the total metolachlor volatilized, especially if soils are dry.

- Regions with subsurface flow pathways had larger surface soil water content if prior precipitation was substantial, and this affected metolachlor volatilization. At this site, when cumulative prior precipitation was $<100 \mathrm{~mm}$, the subsurface flow pathways did not appear to influence surface soil water contents.

- The impact of a moist soil surface on metolachlor volatilization appears to dominate organic matter content. However, when soil moisture contents are low, the location with the higher organic matter content (V2) had the lowest metolachlor vapor losses.

- It may be necessary to develop methods such as remote sensing to better quantify spatial soil water content to couple soil moisture and pesticide vapor flux footprints at similar scales.

\section{References}

Alegria, H.A., and T.J. Shaw. 1999. Rain deposition of atrazine and trifluralin in coastal waters of the South Atlantic Bight. Environ. Sci. Technol. 33:850-856.

Baldocchi, D., B.B. Hicks, and T.P. Meyers. 1988. Measuring biosphere-atmosphere exchanges of biologically related gases with micrometeorological methods. Ecology 69:1331-1340.

Buttle, J.M. 1990. Metolachlor in surface runoff. J. Environ. Qual. 19:531-538.

Choi, M., and J.M. Jacobs. 2007. Soil moisture variability of root zone profiles within SMEX02 remote sensing footprint. Adv. Water Resour. 30:883-896.

De Lannoy, G.J.M., N.E.C. Verhoest, P.R. Houser, and T.J. Gish. 2006. Spatial and temporal characteristics of soil moisture in an intensively monitored agricultural field (OPE3). J. Hydrol. 331:719-730.

Gaynor, J.D., D.C. MacTavish, and W.I. Findlay. 1995. Atrazine and metolachlor loss in surface and subsurface runoff as affected by cultural practices. J. Environ. Qual. 24:246-256.

Gaynor, J.D., C.S. Tan, C.F. Dury, T.W. Welacky, H.Y.F. Ng, and W.D. Reynolds. 2002. Runoff and drainage losses of atrazine, metribuzin, and metolachlor in three management systems. J. Environ. Qual. 31:300-308.

Glotfelty, D.E., A.W. Taylor, B.J. Turner, and W.H. Zoller. 1984. Volatilization of surface applied pesticides from a fallow soil. J. Agric. Food Chem. 32:638-643.

Glotfelty, D.E., M.M. Leech, J. Jersey, and A.W. Taylor. 1989. Volatilization and wind erosion of soil-surface applied atrazine, simazine, alachlor, and toxaphene. J. Agric. Food Chem. 37:546-555.

Gish, T.J., W.P. Dulaney, K.J.S. Kung, C.S.T. Daughtry, J.A. Doolittle, and P.T. Miller. 2002. Use of ground-penetrating radar to identify groundwater pathways at the watershed scale. Soil Sci. Soc. Am. J. 66:1620-1629.

Gish, T.J., C.L. Walthall, C.S.T. Daughtry, and K.-J.S. Kung. 2005. Using soil moisture and spatial yield patterns to identify subsurface flow pathways. J. Environ. Qual. 34:274-286.

Guber, A.K., T.J. Gish, Y.A. Pachepsky, M.T. van Genuchten, C.S.T. Daughtry, T.J. Nicholson, and R.E. Cady. 2008. Temporal stability in soil water content patterns across agricultural fields. Catena 73:125-133.

Jury, W.A., W.F. Spencer, and W.J. Farmer. 1983. Behavior assessment model for trace organics in soil: I. Model description. J. Environ. Qual. 12:558-564.
Jury, W.A., W.F. Spencer, and W.J. Farmer. 1984. Behavior assessment model for trace organics in soil: IV. Review of experimental evidence. J. Environ. Qual. 13:580-586.

Karickhoff, S.W. 1981. Semi-empirical estimation of sorption of hydrophobic pollutants on natural sediments. Chemosphere 10:833-846.

Kuang, Z., L.L. McConnell, A. Torrents, D. Meritt, and S. Tobash. 2003. Atmospheric deposition of pesticides to an agricultural watershed of the Chesapeake Bay. J. Environ. Qual. 32:1611-1622.

Kung, K.-J.S. 1990. Preferential flow in a sandy vadose zone: I. Field observations. Geoderma 46:51-71.

Lyman, W.J., W.F. Reehl, and D.H. Rosenblatt. 1990. Handbook of chemical property estimation methods. Washington, DC, American Chemical Society, p. 4-9, 15-1, and 15-29.

Martin, J.D., C.G. Crawford, and S.J. Larson. 2003. Pesticides in streams: Summary statistics; preliminary results from cycle 1 of the National Water Quality Assessment Program (NAWQA), 1999-2001. Available at: http://water.usgs.gov/nawqa/pnsp/pubs/circ1291/appendix7/ appendix7a-4.mix.xls (verified 20 May 2009).

McConnell, L.L., J.S. LeNoir, S. Datta, and J.N. Seiber. 1998. Wet deposition of current-use pesticides in the Sierra Nevada mountain range, California, USA. Environ. Toxicol. Chem. 17:1908-1916.

National Center for Food and Agricultural Policy. 2004. National pesticide use database. Available at http://cipm.ncsu.edu/croplife/ (verified 20 May 2009).

Prueger, J.H., J.L. Hatfield, and T.J. Sauer. 1999. Field-scale metolachlor volatilization flux estimates from broadcast and banded application methods in central Iowa. J. Environ. Qual. 28:75-81.

Prueger, J.H., T.J. Gish, L.L. McConnell, L.G. McKee, J.L. Hatfield, and W.P. Kustas. 2005. Solar radiation, relative humidity, and soil water effects on metolachlor volatilization. Environ. Sci. Technol. 39:5219-5226.

Rao, P.S.C., and J.M. Davidson. 1980. Estimation of pesticide retention and transformation parameters required in nonpoint source pollution models. p. 23-67. In M.R. Overcash and J.M. Davidson (ed.) Environmental impact of nonpoint source pollution. Ann Arbor Sci. Pub., Ann Arbor, MI.

Rice, C.P., C.B. Nochetto, and P. Zara. 2002. Volailization of trfluralin, atrazine, metolachlor, chlorpyrifos, $\alpha$-endosulfan, and $\beta$-endosulfan from freshly tilled soil. J. Agric. Food Chem. 50:4009-4017.

Seyfried, M.S., and M.D. Murdock. 2004. Measurement of soil water content with a 50-MHz soil dielectric sensor. Soil Sci. Soc. Am. J. 68:394-403.

Seyfried, M.S., and L.E. Grant. 2007. Temperature effects on soil dielectric properties at $50 \mathrm{MHz}$. Vadose Zone J. 6:759-765.

Spencer, W.F., M.M. Cliath, and W.J. Farmer. 1969. Vapor density of soilapplied dieldrin as related to soil-water content, temperature, and dieldrin concentration. Soil Sci. Soc. Am. Proc. 33:509-511.

Spencer, W.F., and M.M. Cliath. 1970. Desorption of Lindane from soil as related to vapor density. Soil Sci. Soc. Am. Proc. 34:574-578.

Taylor, A.W. 1995. The volatilization of pesticide residues. p. 257-306. In T.R. Roberts and P.C. Kearney (ed.) Environmental behavior of agrochemicals. John Wiley \& Sons, New York.

Taylor, A.W., and W.F. Spencer. 1990. Volatilization and vapor transport processes. p. 213-269. In H.H. Cheng (ed.) Pesticides in the soil environment: Processes, impacts, and modeling, SSSA, Madison, WI.

Thurman, E.M., and A.E. Cromwell. 2000. Atmospheric transport, deposition, and fate of triazine herbicides and their metabolites in pristine areas at Isle Royale National Park. Environ. Sci. Technol. 34:3079-3085.

USEPA. 1990. National pesticide survey: Project summary. EPA Report $570990 \mathrm{NPSg}$

USEPA. 2006. Metolachlor: Regulatory determinations support document for selected contaminants from the Second Drinking Water Contaminant Candidate List (CCL 2). EPA Report 815-D-06-007, p. 13-1-13-28.

Van den Berg, F., R. Kubiak, W.G. Benjey, M.S. Majewski, S.R. Yates, G.L. Reeves, J.H. Smelt, and A.M.A. Van der Linden. 1999. Emission of pesticides into the air. Water Air Soil Pollut. 115:195-218.

Verma, S.B. 1990. Micrometeorological methods for measuring surface fluxes of mass and energy. Remote Sens. Rev. 5:99-115.

Wauchope, R.D. 1978. The pesticide content of surface water draining from agricultural fields: A review. J. Environ. Qual. 7:459-472.

Wolters, A., V. Linneman, M. Herbst, M. Klein, A. Schaffer, and H. Vereecken. 2003. Pesticide volatilization from soil: Lysimeter measurements versus predictions of European registration models. J. Environ. Qual. 32:1183-1193. 